\title{
The Effect of Anterior Cruciate Ligament Reconstruction Technique on Graft Signal Intensity at Mid-Term Follow-Up
} Ziga Snoj, ${ }^{1, *}$ Oskar Zupanc, ${ }^{2}$ and Vladka Salapura ${ }^{1}$

${ }^{1}$ Institute of Radiology, University Medical Centre Ljubljana, Ljubljana, Slovenia

${ }^{2}$ Department of Orthopedic Surgery of the Ljubljana University Medical Centre, Ljubljana, Slovenia

"Corresponding author: Ziga Snoj, Institute of Radiology, University Medical Centre Ljubljana, Zaloska 7, Slovenia. Tel: +386-41245052, E-mail: ziga.snoj@gmail.com

Received 2017 May 25; Revised 2017 October 24; Accepted 2017 November 04.

\begin{abstract}
Background: Anterior cruciate ligament reconstruction (ACL-R) technique affects graft positioning. However, how ACL graft positioning affects graft signal intensity (GSI) is yet unknown. The aim of our study was to find out if ACL-R technique affects GSI at mid-term follow-up.

Patients and Methods: A total of 50 patients were included in the study. They underwent 3.0 T MRI of the knee 4-7 years after ACL-R. Patients were divided into two groups according to ACL-R technique (transtibial technique with RIGIDfix fixation [group 1] and anteromedial portal technique with Endobutton fixation [group 2]). GSI, graft failure, graft impingement and graft position were assessed. GSI characteristics were evaluated on proton density turbo spin echo fat saturation images. Graft was divided into two portions - intraarticular portion (IAP) and intraosseous portion (IOP). Intraosseous portion was further divided into two parts - femoral (fIOP) and tibial (tIOP).

Results: Graft failure was identified in 12.0\%. Only 9.8\% showed low signal intensity of the entire graft course. Group 2 showed higher rates of increased graft signal intensity (IGSI) of the IAP and fIOP. Patients with IGSI of the IAP showed more horizontal position of the coronal tibial tunnel. Patients with IGSI of the fIOP showed more horizontal position of the coronal femoral tunnel. Patients with IGSI of the tIOP showed more horizontal position of the sagittal tibial tunnel.

Conclusion: IGSI can be seen in the majority of patients after ACL-R at mid-term follow-up. Our study demonstrates that graft tunnel positioning and graft fixation device may influence GSI.
\end{abstract}

Keywords: Anterior Cruciate Ligament Reconstruction (ACL-R), MRI, Graft Signal Intensity

\section{Background}

In everyday practice it is of great importance to understand the etiology and significance of increased graft signal intensity (IGSI) in order to adequately interpret imaging findings. Early studies described intact anterior cruciate ligament $(\mathrm{ACL})$ graft as having low graft signal intensity (GSI) (1). However, several studies in the past two decades have shown that intact grafts may show variable degrees of IGSI (2-4). In the literature, various underlying causes are associated with IGSI; graft impingement (5), imaging artifacts (6), incomplete maturation of the graft (3), enlargement of the drilling tunnels (7), and degenerative changes (4).

No study has yet evaluated the impact of anterior cruciate ligament reconstruction (ACL-R) technique on IGSI.

\section{Objectives}

The aim of our study was to find out if ACL-R technique affects GSI at mid-term follow-up. Our hypothesis was that GSI is affected by the ACL-R technique.

\section{Patients and Methods}

\subsection{Study Design and Patients}

The national medical ethics committee approved the study and written informed patient consent was obtained for this study. From 2008 to 2010, the orthopedic department at our institution gradually switched from the transtibial (TT) ACL-R technique to anteromedial (AM) portal ACL-R technique. In the period from January 2008 until October 2009, 107 patients underwent TT with RIGIDfix fixation and in the period from November 2008 until July 2010, 132 patients underwent AM with Endobutton fixation. Based on the review of clinical notes, 35 patients from each group met the following study inclusion criteria: (1) autologous quadruple stranded semitendinosusgracillis graft (STGR), (2) no history of prior knee surgery, (3) no history of total meniscectomy or concomitant collateral ligament disruption, (4) 16 - 45 years at operation, (5) sports activity of at least four on Tegner scale prior to the ACL rupture, (6) no readmissions or records of knee related problems after ACL-R and (7) no MR contraindication. Fifty patients were successfully contacted; their demographic characteristics are shown in Table 1. Patients were divided into two groups, patients who underwent TT with RIGIDfix fixation (group 1, $\mathrm{n}=25$ ) and patients who underwent AM with Endobutton fixation (group 2, $\mathrm{n}=25$ ). Range for the 
time from ACL-R to MR examination was from 52.1 to 87.0 months.

\begin{tabular}{|c|c|c|c|}
\hline & Group 1; $(n=25)$ & Group 2; $(n=25)$ & P Value \\
\hline Sex (male:female) & $14: 11$ & 13:12 & \\
\hline Age at ACL-R, y & $28.8 \pm 8.4$ & $29.6 \pm 8.2$ & 0.74 \\
\hline $\begin{array}{l}\text { Age at MR } \\
\text { examination, } y\end{array}$ & $34.8 \pm 8.4$ & $35.1 \pm 8.2$ & 0.92 \\
\hline BMI at ACL-R, $\mathrm{kg} / \mathrm{m}^{2}$ & $23.7 \pm 2.7$ & $24.3 \pm 2.9$ & 0.54 \\
\hline $\begin{array}{l}\text { BMI at MR } \\
\text { examination, } \mathrm{kg} / \mathrm{m}^{2}\end{array}$ & $25.0 \pm 3.2$ & $25.5 \pm 3.4$ & 0.67 \\
\hline $\begin{array}{l}\text { Time from ACL-R to } \\
\text { MR examination, } \\
\text { months }\end{array}$ & $70.9 \pm 9.3$ & $68.2 \pm 8.7$ & 0.16 \\
\hline
\end{tabular}

\subsection{Surgical Technique}

At ACL-R, arthroscopic examination was performed to confirm ACL rupture. In all patients, single-bundle, quadruple stranded STGR auto-grafts were used. In both groups, tibial tunnel was drilled at a sagittal angle of $60^{\circ}$ to the tibial plateau with the use of tibial drill guide (Mitek, Johnson \& Johnson, Norwood, MA, USA). The graft was fixed by using Milagro interference screw (DePuy Mitek, Raynham, MA, USA).

In the TT group, the knee was positioned in $90^{\circ}$ flexion and cannulated end-cutting head design reamer (Mitek, Johnson \& Johnson, Norwood, MA, USA) was introduced transtibially drilling the femoral tunnel to the depth of 25 to $30 \mathrm{~mm}$. In the femoral tunnel, the graft was fixed by using RIGIDfix (Mitek, Johnson \& Johnson, Norwood, MA, USA).

In the AM group, the knee was positioned in $120^{\circ}$ flexion and cannulated end-cutting head design reamer (Mitek, Johnson \& Johnson, Norwood, MA, USA) was passed through the AM portal drilling the femoral tunnel to the depth of 25 to $30 \mathrm{~mm}$. In the femoral tunnel, the graft was fixed by using Endobutton (Smith \& Nephew Endoscopy, Andover, MA, USA).

\subsection{Clinical Assessment}

Patients' sport activity was evaluated according to Tegner activity scale at three different time points (prior to the injury, at ACL-R and at MRI examination) (8). At ACL-R, patients were asked to evaluate their sport activity prior to the injury and as currently active. At MRI examination, the patients were asked to evaluate their current sport activity.
To evaluate patients' perception of knee related problems, the international knee documentation committee (IKDC) questionnaire was presented to the patients at MRI examination (9).

\subsection{MRI Protocol}

MRI was performed with a 3.0 T imager (Magnetom® Trio, Siemens, Erlangen, Germany) by using an 8-channel transmit-receive knee coil (Invivo, Gainesville, FL, USA) in the supine position.

Imaging sequences included proton density(PD) turbo spin echo (TSE) fat saturation (FS) images in three planes (2400/32 [repetition time (TR) msec/echo time (TE) msec], $15 \mathrm{~cm}$ field of view [FOV], $3 \mathrm{~mm} / 1 \mathrm{~mm}$ [slice thickness/interslice gap], $384 \times 384$ matrix, $150^{\circ}$ flip angle, 2 signals acquired).

\subsection{MRI Analysis}

Qualitative image analysis and quantitative image measurements were performed on a Leonardo $®$ workstation (Siemens Medical Solutions, Erlangen, Germany).

The following MRI findings were evaluated:

1. Graft failure was evaluated as ACL graft being ruptured or preserved. A graft was considered ruptured when no intact fibers were seen and fluid signal was interposed between the ends of graft fibers (10). Patients with graft failure were not included in further analysis.

2. Graft impingement was evaluated as the tibial tunnel being placed partially or completely anterior to the most anterior edge of the femoral notch roof, corresponding to the Blumensaat line (10).

3. Graft signal intensity (GSI) was analyzed on PD FS images. ACL graft was divided into two portions - intraarticular portion (IAP) and intraosseous portion (IOP). IAP was further divided into two parts - proximal and distal. The intraosseous portion was further divided into two parts femoral (fIOP) and tibial (tIOP). IGSI was evaluated on PD FS images as present (increase of signal intensity within the substance or absence) (4). IGSI was subclassified as comprising less than $25 \%, 25 \%$ - 50\%, or more than $50 \%$ of the maximal cross sectional area of the graft (4).

4. Graft orientation of the IAP was evaluated on the coronal and sagittal PD FS images and was defined as the angle between the long axis of the graft and the tibial plateau - the sagittal graft angle(SGA) and the coronal graft angle (CGA) (11).

5. The position of the drilling tunnels was evaluated on coronal and sagittal PD FS images. The position of the femoral tunnel was measured in both planes as the angle between the axis of the femoral tunnel and the tibial plateau. The same approach was used to measure the position of the tibial tunnel. 


\subsection{Statistical Analysis}

A Mann-Whitney test was used to compare groups according to Tegner scale. Wilcoxon signed-rank test was used to evaluate Tegner scale according to different time points. Chi-square test was used to compare both groups according to the preservation of ACL graft and evaluation of the presence of IGSI. A Student two-tailed t-test was utilized to compare groups with respect to the continuous variables. To assess intra-rater reliability the evaluated MRI findings were assessed twice in group 1 by the same operator; the reliability for continuous variables was expressed with interclass correlation coefficient (ICC) and the reliability for categorical variables was expressed with Cohen's kappa $(\kappa)$. Continuous variables were expressed as mean $\pm \mathrm{SD}$ and categorical values were expressed as median. Significance was set at $\mathrm{P}<0.05$. The post-hoc power of the primary study endpoints are $\pi=0.77$ for the GSI evaluation of the IAP and $\pi=0.90$ for the GSI evaluation of the IOP. Statistical analysis was performed with SPSS v.17.0 (SPSS Inc., Chicago, Ill, USA).

\section{Results}

\subsection{Clinical Assessment}

There was no difference in Tegner activity scale between the study groups prior to the injury, at ACL-R and at MRI examination $(\mathrm{P}=0.41 ; \mathrm{P}=0.82$ and $\mathrm{P}=0.88$, respectively). Tegner activity scale in group 1 was six prior to the injury, four at ACL-R and six at MRI examination. Tegner activity scale in group 2 was seven prior to the injury, four at ACL-R and six at MRI examination.

Patients in group 1 and 2 showed similar mean IKDC subjective knee score at MRI examination ( $82.5 \pm 17.3$ vs. $81.5 \pm 16.1$, respectively; $\mathrm{P}=0.84$ ).

\subsection{MRI Findings}

Graft failure - Six (12.0\%) patients had ruptured ACL graft. Patients from group 1 tended to have lower graft failure rates than patients from group 2 [one (4.0\%) patient vs. five $(20.0 \%)$ patients; $\mathrm{P}=0.08$ ].

Graft impingement-Graft impingement was seen only in one patient in each group. Very good intra-rater reliability with $\kappa=0.96$ was observed for graft impingement.

GSI - Group 2 showed higher rates of IGSI of the IAP and fIOP (Table 2) (Figures 1 and 2). The subclassification of the IGSI is shown in Table 3. Fifteen (36.6\%) patients had IGSI of the IAP, 35 (85.4\%) had IGSI of the IOP and only 4 (9.8\%) showed low GSI of the entire graft course. The presence of IGSI showed very good intra-rater reliability with $\kappa$ $=0.96$, however the subclassification of IGSI showed moderate intra-rater reliability with $\kappa=0.79$.
Table 2. Findings of the Intrasubstance Anterior Cruciate Ligament (ACL) Graft Signal $^{\mathrm{a}}$

\begin{tabular}{cccc}
\hline & Group 1 & Group 2 & P Value \\
\hline IGSI of the IAP & $4(16.7)$ & $11(55.0)$ & $<0.01$ \\
\hline Proximal part & $1(4.2)$ & $3(15.0)$ & 0.21 \\
\hline Distal part & $0(0)$ & $2(10.0)$ & 0.11 \\
\hline Both & $3(12.5)$ & $6(30.0)$ & 0.15 \\
\hline IGSI of the IOP & $17(70.8)$ & $18(90.0)$ & 0.11 \\
\hline fIOP & $11(45.8)$ & $18(90.0)$ & $<0.01$ \\
\hline tIOP & $14(58.3)$ & $15(75.0)$ & 0.25 \\
\hline Both & $8(33.3)$ & $15(75.0)$ & $<0.01$ \\
\hline
\end{tabular}

Abbreviations: fIOP, femoral intraosseous portion; IAP, intraarticular portion; IGSI, increased graft signal intensity; IOP, intraosseous portion; tIOP, tibial intraosseous portion.

${ }^{\mathrm{a}}$ Values are expressed as No. (\%).

Graft orientation of the IAP - Both groups showed similar mean position of the CGA. However, the SGA was more horizontal in group 2 than in group 1 (Table 4). The intraobserver ICC of the CGA and SGA graft measurements were 0.86 and 0.88 , respectively.

The positions of the drilling tunnels - Both groups showed similar mean positions of the tibial tunnel and the femoral tunnel in the sagittal plane (Table 4). Femoral tunnel in the coronal plane was positioned more horizontally in group 2 than in group 1 (Table 4). The intra-observer ICC for the femoral tunnel in the coronal and sagittal plane were 0.92 and 0.88 , respectively.

Statistical results of the relationships - The relationships between demographic characteristics, continuous variables of the MRI findings, clinical outcome and GSI were performed. In each of the studied graft portions, one significant effect was found (Table 5). Patients with IGSI of the IAP showed more horizontal position of the coronal tibial tunnel ( 15 vs. 29 patients, $69.6^{\circ} \pm 7.8^{\circ}$ vs. $58.9^{\circ} \pm$ $\left.20.7^{\circ} ; \mathrm{P}=0.02\right)$. Patients with IGSI of the fIOP showed more horizontal position of the coronal femoral tunnel (29 vs. 15 patients, $52.0^{\circ} \pm 5.4^{\circ}$ vs. $\left.62.3^{\circ} \pm 9.4^{\circ} ; \mathrm{P}<0.01\right)$. Patients with IGSI of the tIOP showed more horizontal position of the sagittal tibial tunnel ( 24 vs. 20 patients, $60.7^{\circ} \pm 7.8^{\circ}$ vs. $\left.65.6^{\circ} \pm 7.1^{\circ} ; \mathrm{P}=0.03\right)$.

\section{Discussion}

In the present study, MRI graft measurements and clinical outcome were undertaken in order to compare ACL-R techniques and to find out whether any relationship exists with GSI. The most important finding of our study was the difference in IGSI between study groups. 

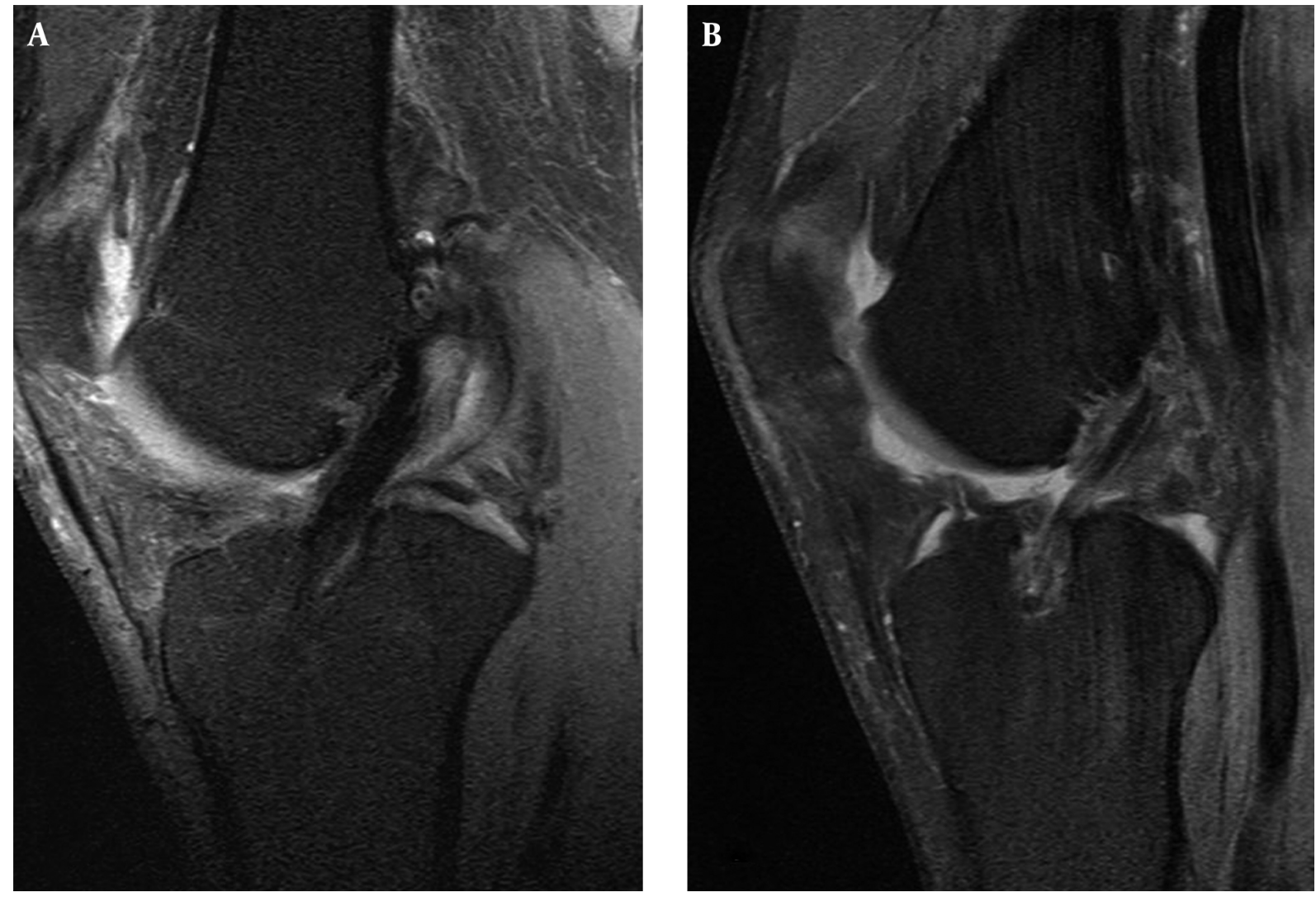

Figure 1. Sagittal proton density (PD) fat saturation (FS) images in (A) a 49-year-old man from group 1 and (B) a 27-year-old woman from group 2 show the difference in the signal intensity of the intraarticular and the tibial intraosseous portion of the anterior cruciate ligament (ACL) graft.

Table 3. Subclassification of the Increased Intrasubstance Graft Signal ${ }^{\mathrm{a}}$

\begin{tabular}{|c|c|c|}
\hline & Group 1 & Group 2 \\
\hline \multicolumn{3}{|l|}{ IAP } \\
\hline Less than 25 & $2(50)$ & $2(18.2)$ \\
\hline $25-50$ & $2(50)$ & $5(45.5)$ \\
\hline More than 50 & $0(0.0)$ & $4(36.4)$ \\
\hline
\end{tabular}

IOP

\begin{tabular}{|c|c|c|c|c|}
\hline & fIOP & tIOP & fIOP 18 & tIOP 15 \\
\hline Less than 25 & $3(27.2)$ & $5(35.7)$ & $7(38.9)$ & $1(6.7)$ \\
\hline $25-50$ & $4(36.4)$ & $3(21.4)$ & $5(27.8)$ & $4(26.7)$ \\
\hline More than 50 & $4(36.4)$ & $6(42.9)$ & $6(33.3)$ & $10(66.6)$ \\
\hline
\end{tabular}

Abbreviations: fIOP, femoral intraosseous portion; IAP, intraarticular portion; IOP, intraosseous portion; tIOP, tibial intraosseous portion.

${ }^{\mathrm{a}}$ Values are expressed as No. (\%).

Causes of graft failure are multifactorial with the most important being trauma, technical error and failure of graft incorporation (12). It has not yet been determined which fixation method and what position of the drilling tunnels offers a lower rate of graft failure $(12,13)$. Graft failure rate in our study was $12 \%$ and the result is compara- 

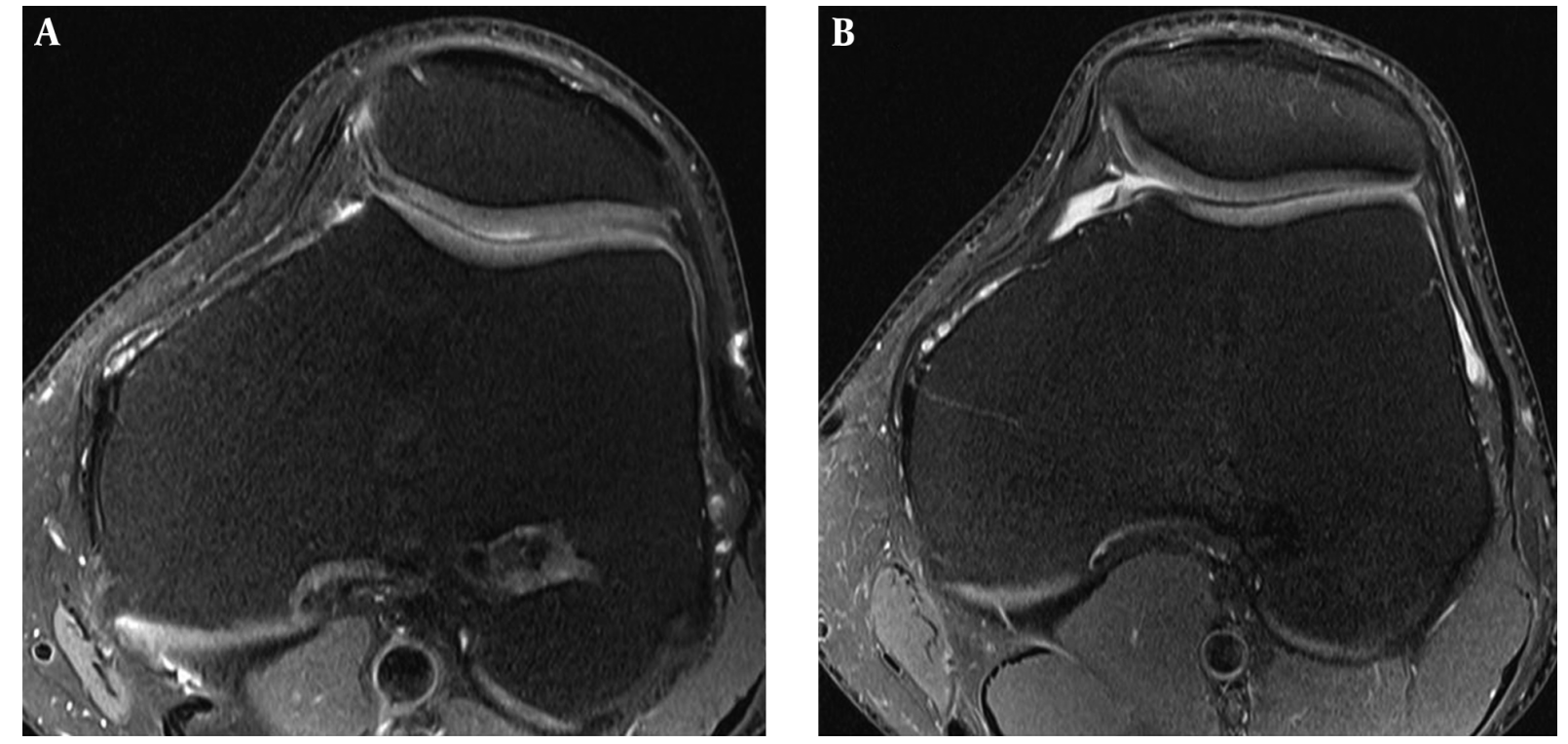

Figure 2. Axial proton density (PD) fat saturation (FS) images in (A) a 45-year-old man from group 2 and (B) a 24 -year-old man from group 2 show the difference in the signal intensity of the femoral intraosseous portion of the anterior cruciate ligament (ACL) graft.

Table 4. Positions of Drilling Tunnels and Orientation of the Intraarticular Portion of Anterior Cruciate Ligament (ACL) Graft ${ }^{\mathrm{a}}$

\begin{tabular}{lccc}
\hline & Group 1, $^{\circ}$ & Group 2, $^{\circ}$ & P Value \\
\hline CGA & $77.2 \pm 8.8$ & $74.6 \pm 7.4$ & 0.30 \\
\hline SGA & $60.4 \pm 5.7$ & $56.5 \pm 5.0$ & 0.02 \\
\hline Tibial tunnel, sagittal position & $62.8 \pm 7.2$ & $62.5 \pm 8.7$ & 0.93 \\
\hline Tibial tunnel, coronal position & $58.0 \pm 5.8$ & $60.8 \pm 6.7$ & 0.70 \\
\hline Femoral tunnel, sagittal position & $63.8 \pm 8.5$ & $67.4 \pm 11.6$ & 0.25 \\
\hline Femoral tunnel, coronal position & $61.0 \pm 7.2$ & $47.7 \pm 7.2$ & $<0.01$ \\
\hline
\end{tabular}

Abbreviations: CGA, coronal graft angle, SGA, sagittal graft angle.

${ }^{\mathrm{a}}$ Values are expressed as mean $\pm \mathrm{SD}$.

ble with previous papers, which reported graft failure of quadruple stranded STGR in $4 \%-15.3 \%(13,14)$. Although short of statistical significance, group 2 tended to have higher rate of graft failure than group 1.

Comparing study groups in respect to graft position and clinical evaluation, similar findings were found in previously reported papers studying TT and AM $(15,16)$. The sagittal graft position of the IAP and the coronal position of the femoral drilling tunnel in group 2 were found to be more horizontal than in group 1 . There were no differences in Tegner activity scale and IKDC score between the study groups. However, significant difference in the rate of IGSI between the study groups was observed.

GSI in the early postreconstruction period has been
Table 5. P Values of the Relationships Between ACL Graft Signal Evaluations and Continuous Variables

\begin{tabular}{lccc}
\hline & $\begin{array}{c}\text { ACL Graft } \\
\text { Signal of the } \\
\text { IAP }\end{array}$ & $\begin{array}{c}\text { ACL Graft } \\
\text { Signal of the } \\
\text { flOP }^{\mathbf{a}}\end{array}$ & $\begin{array}{c}\text { ACL Graft } \\
\text { Signal of the } \\
\text { tIOP }^{\mathbf{a}}\end{array}$ \\
\hline $\begin{array}{l}\text { Tibial tunnel, } \\
\text { sagittal } \\
\text { position }\end{array}$ & 0.92 & 0.65 & 0.03 \\
$\begin{array}{l}\text { Tibial tunnel, } \\
\text { coronal } \\
\text { position }\end{array}$ & 0.02 & 0.25 & 0.12 \\
$\begin{array}{l}\text { Femoral } \\
\text { tunnel, } \\
\text { coronal } \\
\text { position }\end{array}$ & 0.14 & 0.43 \\
\hline $\begin{array}{l}\text { Abbreviations: fIOP, femoral intraosseous portion; IAP, intraarticilar portion; } \\
\text { IOP, intraosseous portion; tIOP, tibial intraosseous portion. } \\
\text { a Calculated for the patients with preserved anterior cruciate ligament (ACL) } \\
\text { graft (24 patients in group 1 and 20 patients in group 2). }\end{array}$ & \\
\hline
\end{tabular}

well studied, however few studies evaluated the GSI at midor long-term follow-up $(2,4,17)$. In short-term studies, the entire course of the graft has been studied and it was shown that IGSI is a dynamic process of healing and by 2-years postreconstruction, the graft should resume uniformly low GSI on MRI $(18,19)$. Saupe et al. evaluated IAP of the graft 4 to 12 years after ACL-R and found IGSI on intermediate-weighted images in $70 \%$ and on $\mathrm{T} 2$-weighted images in $64 \%$ of the patients. However, no clinical or functional correlation with IGSI was found (4). Horton et al. 
evaluated IAP of the graft 6 months to 10 years after ACL$\mathrm{R}$ and found IGSI on PD-weighted images in $40 \%$ of the patients (17). Biercevicz et al. showed that the median GSI significantly contributed to the predictions of functional and patient-orientated outcome at 5-year follow-up (2). Furthermore, previous studies have shown better knee performance and surgical outcome in grafts with lower GSI (2, 20). In our study, IGSI of the IAP was observed in $36.6 \%$, and only $9.8 \%$ of patients showed low GSI of the entire graft course. Moreover, there was a statistically significant difference between the study groups in IGSI of the IAP. However, there was no difference in the clinical outcome between the study groups and no relationship was found between IGSI and clinical outcome.

We found no previous studies evaluating IGSI of the IOP at mid-or long-term follow-up. In our study, IGSI of the IOP was observed in $85.4 \%$ of the patients. Group 2 showed significantly higher rates of IGSI of the fIOP. However, there was no difference between groups in IGSI of the tIOP. Previous studies showed a difference in the healing process between the drilling tunnels with tendon-to-bone healing being faster in the tibial than the femoral tunnel. However, at our follow-up time, this process should have already subsided $(2,21)$. Farshad-Amacker et al. observed that recent trend toward "anatomic" femoral and tibial footprints affects signal properties of the graft (22). They described prolonged hyperintensity in the delayed perioperative period, however uncertain if IGSI is due to plastic deformation or higher tension of the graft (22). Our results suggest there appears to be a difference in IGSI between the tibial and femoral tunnel, which may be attributed to the femoral tunnel positioning and graft fixation.

A statistically significant effect was found between the coronal position of the tibial tunnels and IGSI of the tIOP in our study. Previous studies have shown that the angle of the femoral and tibial tunnels strongly affects graft tension $(23,24)$. Lower graft tension is obtained with femoral and tibial tunnels with angles of $60^{\circ}(23,24)$. Patients in our study showed IGSI of the IAP when coronal tibial tunnel was positioned closer to $60^{\circ}$ and showed low GSI when the coronal tibial tunnel was positioned closer to $70^{\circ}$. Moreover, statistically significant effect was found between the coronal position of the femoral tunnel and IGSI of the fIOP. This result has to be interpreted with caution, since patients from group 2 showed higher rates of IGSI of the fIOP and had femoral tunnel positioned more horizontally than group 1. It should not be neglected that this result could as well be attributed to graft fixation.

There were some limitations in the study. The first and likely most important limitation was that different femoral fixation and different femoral drilling techniques were used between groups. The findings of our study need to be interpreted critically to what degree the findings could be attributed to a difference in femoral fixation or difference in femoral tunnel drilling. The second limitation of our study was that clinical and radiological characteristics were reviewed retrospectively and no objective assessment of the knee was performed with lack of surgical conformation of the findings in the study. Another limitation of our study was the consequence of potential study-selection bias with patient cohorts being designed with presumption of good clinical outcome and not seeking medical reassessment. However, the cohort study is likely representative of a spectrum of postreconstruction findings in patients at mid-term follow-up after ACL-R.

In conclusion, IGSI can be seen on PD FS images in the majority of patients after ACL-R at mid-term follow-up. Our study demonstrates that graft tunnel positioning and graft fixation device may influence GSI.

\section{Acknowledgments}

We acknowledge radiological technicians at our institution for direct technical assistance, including help with patients and equipment. We acknowledge M. Stevanac for assistance with statistical analysis.

\section{Footnote}

Conflicts of Interest: Regarding this paper there are no financial or other relationships that might lead to conflict of interest.

\section{References}

1. Rak KM, Gillogly SD, Schaefer RA, Yakes WF, Liljedahl RR. Anterior cruciate ligament reconstruction: evaluation with MR imaging. Radiology.1991;178(2):553-6. doi: 10.1148/radiology.178.2.1987623. [PubMed: 1987623].

2. Biercevicz AM, Akelman MR, Fadale PD, Hulstyn MJ, Shalvoy RM, Badger GJ, et al. MRI volume and signal intensity of ACL graft predict clinical, functional, and patient-oriented outcome measures after ACL reconstruction. Am J Sports Med. 2015;43(3):693-9. doi: 10.1177/0363546514561435. [PubMed: 25540298].

3. Murakami Y, Sumen Y, Ochi M, Fujimoto E, Deie M, Ikuta Y. Appearance of anterior cruciate ligament autografts in their tibial bone tunnels on oblique axial MRI. Magn Reson Imaging. 1999;17(5):679-87. [PubMed: 10372521].

4. Saupe N, White LM, Chiavaras MM, Essue J, Weller I, Kunz M, et al. Anterior cruciate ligament reconstruction grafts: MR imaging features at long-term follow-up-correlation with functional and clinical evaluation. Radiology. 2008;249(2):581-90. doi: 10.1148/radiol.2492071651. [PubMed: 18769016].

5. Howell SM, Knox KE, Farley TE, Taylor MA. Revascularization of a human anterior cruciate ligament graft during the first two years of implantation. Am J Sports Med. 1995;23(1):42-9. doi: 10.1177/036354659502300107. [PubMed: 7726349]. 
6. Bydder M, Rahal A, Fullerton GD, Bydder GM. The magic angle effect: a source of artifact, determinant of image contrast, and technique for imaging. J Magn Reson Imaging. 2007;25(2):290-300. doi: 10.1002/jmri.20850. [PubMed: 17260400].

7. Jansson KA, Harilainen A, Sandelin J, Karjalainen PT, Aronen HJ, Tallroth $\mathrm{K}$. Bone tunnel enlargement after anterior cruciate ligament reconstruction with the hamstring autograft and endobutton fixation technique. A clinical, radiographic and magnetic resonance imaging study with 2 years follow-up. Knee Surg Sports Traumatol Arthrosc. 1999;7(5):290-5. doi: 10.1007/s001670050166. [PubMed: 10525698].

8. Briggs KK, Kocher MS, Rodkey WG, Steadman JR. Reliability, validity, and responsiveness of the Lysholm knee score and Tegner activity scale for patients with meniscal injury of the knee. J Bone Joint Surg Am. 2006;88(4):698-705. doi: 10.2106/JBJS.E.00339. [PubMed:16595458].

9. Higgins LD, Taylor MK, Park D, Ghodadra N, Marchant M, Pietrobon $\mathrm{R}$, et al. Reliability and validity of the International Knee Documentation Committee (IKDC) Subjective Knee Form. Joint Bone Spine. 2007;74(6):594-9. doi: 10.1016/j.jbspin.2007.01.036. [PubMed: 17888709].

10. Papakonstantinou O, Chung CB, Chanchairujira K, Resnick DL. Complications of anterior cruciate ligament reconstruction: MR imaging. Eur Radiol. 2003;13(5):1106-17. doi: 10.1007/s00330-002-1622-9. [PubMed: 12695835].

11. Snoj Z, Zupanc O, Strazar K, Salapura V. A descriptive study of potential effect of anterior tibial translation, femoral tunnel and anterior cruciate ligament graft inclination on clinical outcome and degenerative changes. Int Orthop. 2017;41(4):789-96. doi: 10.1007/s00264-0163386-x. [PubMed: 28064350].

12. Mayr R, Rosenberger R, Agraharam D, Smekal V, El Attal R. Revision anterior cruciate ligament reconstruction: an update. Arch Orthop Trauma Surg. 2012;132(9):1299-313. doi: 10.1007/s00402-012-1552-1. [PubMed: 22669543].

13. Conte EJ, Hyatt AE, Gatt CJ, Dhawan A. Hamstring autograft size can be predicted and is a potential risk factor for anterior cruciate ligament reconstruction failure. Arthroscopy. 2014;30(7):882-90. doi: 10.1016/j.arthro.2014.03.028. [PubMed: 24951356].

14. Buchner M, Schmeer T, Schmitt H. Anterior cruciate ligament reconstruction with quadrupled semitendinosus tendon - minimum 6 year clinical and radiological follow-up. Knee. 2007;14(4):321-7. doi: 10.1016/j.knee.2007.04.006. [PubMed: 17512735].

15. Hantes ME, Zachos VC, Liantsis A, Venouziou A, Karantanas AH, Malizos KN. Differences in graft orientation using the transtibial and anteromedial portal technique in anterior cruciate ligament recon- struction: a magnetic resonance imaging study. Knee Surg Sports Traumatol Arthrosc. 2009;17(8):880-6. doi: 10.1007/s00167-009-0738-8. [PubMed: 19238359].

16. Harner CD, Honkamp NJ, Ranawat AS. Anteromedial portal technique for creating the anterior cruciate ligament femoral tunnel. Arthroscopy. 2008;24(1):113-5. [PubMed: 18188873].

17. Horton LK, Jacobson JA, Lin J, Hayes CW. MR imaging of anterior cruciate ligament reconstruction graft. AJR Am J Roentgenol. 2000;175(4):1091-7. doi: 10.2214/ajr.175.4.1751091. [PubMed: 11000171].

18. Casagranda BU, Maxwell NJ, Kavanagh EC, Towers JD, Shen W, Fu FH. Normal appearance and complications of double-bundle and selective-bundle anterior cruciate ligament reconstructions using optimal MRI techniques. AJR Am J Roentgenol.2009;192(5):1407-15. doi: 10.2214/AJR.08.1185. [PubMed: 19380570].

19. Ntoulia A, Papadopoulou F, Zampeli F, Ristanis S, Argyropoulou M, Georgoulis A. Evaluation with contrast-enhanced magnetic resonance imaging of the anterior cruciate ligament graft during its healing process: a two-year prospective study. Skeletal Radiol. 2013;42(4):541-52. doi: 10.1007/s00256-012-1534-y. [PubMed: 23229627].

20. Biercevicz AM, Miranda DL, Machan JT, Murray MM, Fleming BC. In Situ, noninvasive, $\mathrm{T} 2$-weighted MRI-derived parameters predict ex vivo structural properties of an anterior cruciate ligament reconstruction or bioenhanced primary repair in a porcine model. Am J Sports Med. 2013;41(3):560-6. doi: 10.1177/0363546512472978. [PubMed: 23348076].

21. Nakase J, Kitaoka K, Toratani T, Kosaka M, Ohashi Y, Tsuchiya H. Grafted tendon healing in femoral and tibial tunnels after anterior cruciate ligament reconstruction. J Orthop Surg (Hong Kong). 2014;22(1):65-9. doi: 10.1177/230949901402200117. [PubMed: 24781617].

22. Farshad-Amacker NA, Potter HG. MRI of knee ligament injury and reconstruction. J Magn Reson Imaging. 2013;38(4):757-73. doi: 10.1002/jmri.24311. [PubMed: 24129921].

23. Pena E, Calvo B, Martinez MA, Palanca D, Doblare M. Influence of the tunnel angle in ACL reconstructions on the biomechanics of the knee joint. Clin Biomech (Bristol, Avon). 2006;21(5):508-16. doi: 10.1016/j.clinbiomech.2005.12.013. [PubMed: 16472892].

24. Simmons R, Howell SM, Hull ML. Effect of the Angle of the Femoral and Tibial Tunnels in the Coronal Plane and Incremental Excision of the Posterior Cruciate Ligament on Tension of an Anterior Cruciate Ligament Graft. J Bone Joint Surg Am Volume. 2003;85(6):1018-29. doi: 10.2106/00004623-200306000-00006. 